\title{
Retinal pigment epithelium transplantation: concepts, challenges, and future prospects
}

\begin{abstract}
The retinal pigment epithelium (RPE) is a single layer of cells that supports the light-sensitive photoreceptor cells that are essential for retinal function. Age-related macular degeneration (AMD) is a leading cause of visual impairment, and the primary pathogenic mechanism is thought to arise in the RPE layer. RPE cell structure and function are well understood, the cells are readily sustainable in laboratory culture and, unlike other cell types within the retina, RPE cells do not require synaptic connections to perform their role. These factors, together with the relative ease of outer retinal imaging, make RPE cells an attractive target for cell transplantation compared with other cell types in the retina or central nervous system. Seminal experiments in rats with an inherited RPE dystrophy have demonstrated that RPE transplantation can prevent photoreceptor loss and maintain visual function. This review provides an update on the progress made so far on RPE transplantation in human eyes, outlines potential sources of donor cells, and describes the technical and surgical challenges faced by the transplanting surgeon. Recent advances in the understanding of pluripotent stem cells, combined with novel surgical instrumentation, hold considerable promise, and support the concept of RPE transplantation as a regenerative strategy in AMD.
\end{abstract}

Eye (2015) 29, 992-1002; doi:10.1038/eye.2015.89; published online 5 June 2015

\section{Introduction}

Age-related macular degeneration (AMD) is the leading cause of visual impairment in the developed world. ${ }^{1}$ The prevalence increases with age and AMD affects up to one third of those aged over 75 years. $^{2}$ Recent advances in anti-Vascular Endothelial Growth Factor
(anti-VEGF) therapy for AMD have revolutionised the management of neovascular AMD (nvAMD). 3,4 However, initial enthusiasm for this therapy has been dampened by the realisation that up to one fifth of patients treated for nvAMD will develop geographic atrophy, ${ }^{5}$ resulting in visual impairment due to loss of photoreceptor cells. Therefore, therapy to combat the development of dry AMD as well as nvAMD is needed. At present there is no effective treatment for dry AMD, which is the more prevalent form of the disease. ${ }^{6}$ As the primary pathogenic process in AMD appears to occur within the complex of the retinal pigment epithelium (RPE), Bruch's Membrane (BrM), and choriocapillaris, a logical approach would be to repair the RPE via either transplantation or translocation of RPE cells.

The RPE consists of a monolayer of highly specialised cuboidal cells that lie between BrM and the outer neurosensory retina (see Figure 1). When viewed from above the cells appear hexagonal, and are joined together by tight junctions (zonulae occludentes), which block the free passage of ions and water. The RPE is therefore the second site of the blood retinal barrier, the first site being the capillary endothelium of the retinal vessels. The most important function of the RPE is the regeneration of bleached opsins, which occurs in the RPE cell cytosol. The RPE has a number of other essential roles including phagocytosis, transepithelial transport, secretion of growth factors, absorption of light, and protection against photo-oxidation. ${ }^{7}$

The polarity of the RPE cell is essential for ion transport. The intercellular tight junctions establish a strong barrier between the subretinal space and the choroid, such that paracellular resistance is 10 times higher than transcellular resistance. 8,9 The high metabolic activity of the photoreceptors leads to the generation of a large amount of water and the intraocular pressure 
a

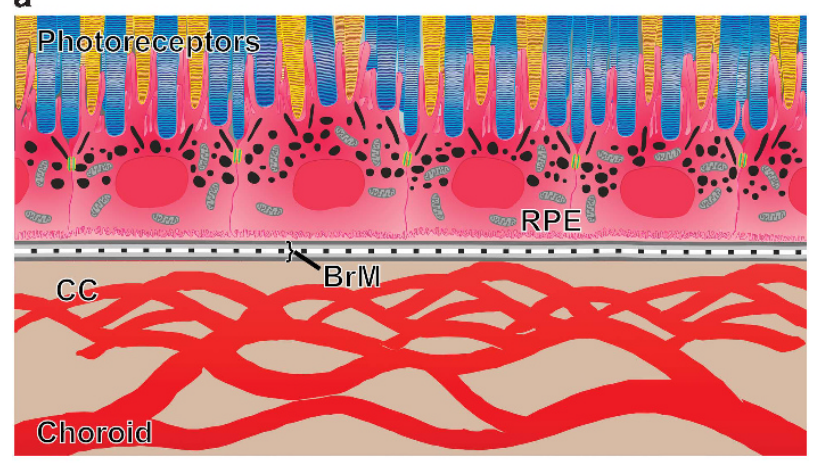

b

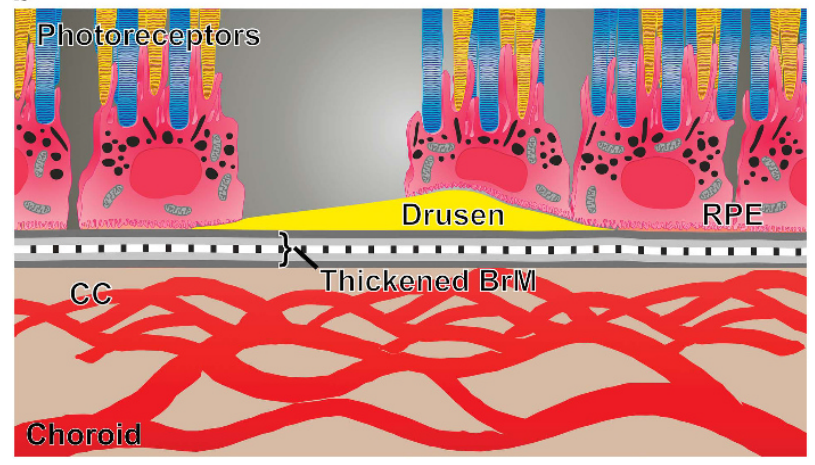

Figure 1 (a) Healthy RPE: healthy RPE exists as a polarised monolayer with tight junctions (green). Melanin is located in the apical cytoplasm and acts to absorb scattered light, thereby improving the optical quality of the eye. Microvilli on the apical RPE membrane interdigitate with the photoreceptors (rods shown in blue; cones shown in yellow). Microvilli allow phagocytosis of the shed photoreceptor outer segments and recycling of the visual pigments. The tight junctions ensure that the RPE can maintain its function as the outer blood retinal barrier. Bruch's membrane $(\mathrm{BrM})$ is a pentilaminar structure; the innermost layer of BrM is formed by the basement membrane of the RPE. The outer layer of $\mathrm{BrM}$ is formed by the basement membrane of the choriocapillaris (CC). Breaches of BrM lead to growth of choroidal vessels into the sub-RPE and subretinal space, known as choroidal neovascularisation. (b) RPE degeneration in AMD: BrM is thickened, impairing diffusion between the choriocapillaris and the neurosensory retina. Drusen are clinically visible deposits that occur beneath the RPE. RPE cell death occurs, and there is loss of tight junctions between the remaining RPE cells, resulting in a discontinuous cell layer. These changes all lead to secondary photoreceptor cell loss, resulting in visual impairment.

causes a net flow of water through the retina from the vitreous. ${ }^{7}$ By transporting ions and water from its apical side to its basolateral surface, the RPE cell ensures the removal of water from the subretinal space but also establishes an adhesive force between the retina and the RPE. ${ }^{7}$

When considering the RPE as a layer, rather than individual cells, it is evident that the ability to perform its many functions is reliant on two factors. First, the RPE layer must be a confluent monolayer, with intercellular tight junctions. Second, the cells must be polarised. Both of these factors are therefore reliant on the RPE basement membrane, which itself forms the innermost layer of BrM, an acellular structure first described in 1844 but characterised in detail in 1961 by Hogan. ${ }^{10}$ BrM has five distinct layers: RPE basement membrane; inner collagenous layer; elastin layer; outer collagenous layer; and the basement membrane of the choriocapillaris. BrM has three main functions: to regulate diffusion between RPE and choroid; to provide physical support for RPE adhesion, migration and, possibly, differentiation; and to create a barrier between retina and choroid, thereby preventing cellular migration from one tissue to the other. During the development of RPE transplantation techniques, the importance of BrM has perhaps been overlooked, which may account for the limited success thus far.

\section{RPE transplantation}

Human RPE cells were first isolated and characterised over 30 years ago. ${ }^{11-13}$ RPE cell structure and function are well understood, the cells are readily sustainable in culture under laboratory conditions, and unlike other cell types within the retina, RPE cells do not require synaptic connections to perform their role. These factors, together with the relative ease of imaging with ophthalmoscopy and optical coherence tomography (OCT) scanning, make RPE cells an attractive target for cell transplantation compared with other cell types in the retina or central nervous system. Compared with other forms of cell replacement therapy, the number of cells required for a given lesion site is relatively small. ${ }^{14} \mathrm{RPE}$ replacement would prevent secondary photoreceptor degeneration, thereby preserving visual function.

Seminal experiments by Li and Turner ${ }^{15}$ used the Royal College of Surgeons (RCS) rat, an animal model of retinal dystrophy, to demonstrate proof of principle of RPE transplantation. The inherited retinal degeneration within the RCS rat was first discovered in 1938 but it was only in 1962 that Dowling and Sidman ${ }^{16}$ discovered an accumulation of outer segments on electron microscopy, suggesting abnormal phagocytosis by the RPE. In 2000, $\mathrm{D}^{\prime} \mathrm{Cruz}$ et $a l^{17}$ discovered that the RCS strain had a defect in the merTK gene and is therefore unable to produce RPE cells that phagocytose shed rod outer segments; this results in photoreceptor death and degeneration of the neurosensory retina within 2 months. However, Li and Turner ${ }^{15}$ demonstrated that subretinal injection of healthy RPE cells allows preservation of the outer nuclear, outer plexiform, and photoreceptor layers. Since then, successful RPE transplantation has also been demonstrated in RPE65 knockout mice that are unable to isomerise all-trans-retinal to 11 -cis-retinal. ${ }^{18}$

Surgical strategies to allow RPE transplantation in humans arose primarily from the absence of effective treatments for nvAMD prior to the development of 
anti-VEGF intravitreal injections. Submacular surgery aimed to remove the subfoveal choroidal neovascular membrane (CNV) and any associated haemorrhage, and the first randomised controlled trial to evaluate this technique, the Submacular Surgery Trial, was initiated in 1998. However the visual outcomes were poor and this disappointing result was attributed to mechanical removal of the RPE at the time of CNV excision. ${ }^{19}$ Since then, three approaches to RPE transplantation have been attempted:

- Macular translocation

- Autologous RPE-Choroid Patch graft

- Subretinal injection of a suspension of autologous RPE cells

\section{Macular translocation}

Macular translocation is a procedure in which the neurosensory retina is surgically detached, rotated, and reattached so that the macula, and in particular the fovea, is repositioned from an area of diseased RPE to an area of healthy RPE. ${ }^{20}$ Therefore, although the RPE itself is not moved, macular translocation surgery can be regarded as a functional RPE transplantation. This procedure can confer long-term visual stability, and in a significant proportion of patients leads to an improvement in both visual acuity ${ }^{21}$ and quality of life. ${ }^{22}$ Of interest, in a series of seven patients undergoing macular translocation for nonexudative AMD, new geographic atrophy was reported in the new subfoveal RPE of one patient. ${ }^{23}$ All patients undergoing macular translocation require further surgery to reposition extraocular muscles to prevent intractable torsional diplopia and the large retinotomies can have significant complications including retinal detachment, proliferative vitreoretinopathy (PVR), macular pucker, and macular hole. ${ }^{21}$ Owing to the high rate of complications, macular translocation surgery has been abandoned by clinicians.

\section{Autologous RPE-choroid patch graft}

Numerous investigators have attempted autologous RPE sheet transplantation, with the aim of using healthy peripheral RPE, on a bed of BrM and partial thickness choroid, and moving the multilayered patch graft to the submacular space. Peyman et al were the first to describe this technique, and report two patients who underwent vitrectomy and CNV excision, combined with RPE transplantation. Visual acuity improved in the patient that received an autologous pedicle RPE graft, while the patient that received RPE and BrM transplant from an enucleated donor eye did not improve. ${ }^{24}$ Stanga et al operated on six patients, and performed vitrectomy and CNV excision with translocation of RPE/BrM from the paramacular area to the subfoveal space. Using a small retinotomy, they fashioned a free RPE/choroid graft in five patients and a pedicled RPE/choroid graft in one patient, followed by air fluid exchange, and face down posturing. Four of the six patients could detect a fixation target projected onto the fovea overlying the translocated RPE, although none of the patients showed any improvement in visual acuity. Three out of six patients experienced significant complications, including subretinal bleeding, PVR-related total retinal detachment, and insertion of an upside-down RPE graft. ${ }^{25}$ Later studies used grafts from the mid peripheral retina, rather than from the edge of the macular RPE defect.

Van Meurs et al also used an internal approach in six patients undergoing subfoveal CNV excision with transplantation of a full thickness patch of RPE and choroid from under the peripheral retina, to the subfoveal space, to cover the excision site. ${ }^{26}$ Four of the six patients showed improvement in visual acuity but this technique still carries with it a significant risk of intraocular haemorrhage, retinal detachment, and PVR. Van Meurs' group recently published the long-term outcomes of 133 patients who underwent CNV excision followed by autologous RPEChoroid grafting. The postoperative PVR rate in this cohort was $10 \%$. The visual acuity outcomes overall were modest but four years after surgery, $5 \%$ of patients had Best Corrected Visual Acuity [BCVA] better than 20/40. ${ }^{27}$

\section{Submacular injection of RPE cell suspension}

In a series of 14 eyes, Binder et al performed pars plana vitrectomy, and created a retinotomy nasal to the optic disc to allow formation of a subretinal bleb. Using a blunt instrument, RPE cells from this area were mobilised, aspirated into a micropipette, and then transplanted over an RPE defect in the macula, ${ }^{28}$ but the dissociated RPE cells were unable to attach to the damaged BrM under the fovea. However, RPE cells from the extramacular site in the peripheral retina were able to restore RPE continuity, because of their ability to divide and adhere to undamaged BrM. This observation suggests that it is the damaged host BrM that is the limiting factor for adherence of isolated cells, and not the age of the RPE donor cells. Furthermore, in vitro studies have shown that embryonic RPE cells can adhere to normal, but not aged, BrM from post-mortem specimens. ${ }^{29}$ These age-related changes in BrM also represent one of the critical differences between human subjects and laboratory animals in which many of the successes of RPE transplantation experiments have been reported, because the latter are generally young and have a healthy BrM. ${ }^{15,30,31}$ 
The inference from these findings is that successful RPE transplantation for AMD must take replacement of BrM into consideration. ${ }^{32}$

\section{Surgical challenges to RPE transplantation}

In his editorial, Gouras and Lopez ${ }^{33}$ noted that the greatest challenge in human RPE cell transplantation lies in the microsurgical technology to enable subretinal surgery. This review will evaluate the challenges facing by the vitreoretinal surgeon and will address four main areas:

- Choice of approach: external (transchoroidal) vs internal (transvitreal)

- Sources of donor RPE cells

- Types of surgical instrumentation

- Prevention and control of PVR and recurrent retinal detachment

\section{Surgical approach: external vs internal}

The first description of RPE transplantation was by Gouras et al, who transplanted cultured ${ }^{3} \mathrm{H}$ thymidinelabelled human RPE cells on to denuded BrM in owl monkeys. ${ }^{34}$ The investigators used an open-sky technique: the cornea was removed, and the globe was open for the duration of the procedure. As a result, the investigators experienced difficulties reattaching the neurosensory retina. ${ }^{34}$ Following modification of the technique to a closed-eye method, consisting of pars plana vitrectomy, retinotomy, and delivery of cells through a pipette, early spontaneous retinal reattachment was achieved. ${ }^{35}$ In both of these studies, donor RPE cells successfully attached to BrM and some phagocytosis of photoreceptor outer segments could be demonstrated. Following this, a number of investigators have continued to use an internal transvitreal approach, involving pars plana vitrectomy, whereas others favour an external approach involving dissection of posterior sclera and transsclerochoroidal subretinal injection of RPE cells. The external approach was first described in the human eye in 1975 by Peyman et al, ${ }^{36}$ who performed a scleralchorioretinal biopsy in a patient with suspected malignant melanoma. Choroidal haemorrhage was avoided by extensive diathermy but moderate vitreous loss occurred through the wound. This technique was subsequently adapted for RPE collecting in pigs $^{37}$ and rabbits. ${ }^{38}$ However, several investigators have utilised an internal approach in humans, consisting of pars plana vitrectomy, surgical excision of subfoveal CNV, followed by translocation of dissociated RPE cells ${ }^{28}$ or an $\mathrm{RPE} / \mathrm{BrM} /$ choroid graft, $^{24-26}$ either free or pedicled.

The external approach is preferable in animal studies, especially in rodents, where the globe is small, the lens is large, and there is no true vitreous cavity to operate within (see Figure 2). ${ }^{39}$ However this technique not only requires rupture of $\mathrm{BrM}$ but also causes choroidal trauma, leading to the risk of severe intraocular or suprachoroidal haemorrhage, and may possibly lead to inflammation and immune responses that would not occur with the transvitreal approach. In larger eyes, the internal surgical approach is considerably easier. Wongpichedchai et al ${ }^{38}$ compared the external vs internal approaches in rabbits, and noted that although similar results were achieved, access to the posterior pole using the external approach was difficult, and required disinsertion of a rectus muscle. In contrast, pars plana vitrectomy is a commonly performed procedure in the developed world, with an estimated 100000 procedures performed in the USA each year, ${ }^{40}$ and around 20000 in the UK. ${ }^{41}$ Therefore, the internal approach may be more appropriate for the human eye, allowing use of existing surgical skills, experience and instrumentation.

\section{Sources of cells}

Although the aim of cell transplantation is to restore RPE function and prevent photoreceptor loss, the transplanted cells do not necessarily need to be RPE cells. Subretinal injection of iris pigment epithelial (IPE) cells, ${ }^{42}$ Schwann cells, ${ }^{43}$ human central nervous system stem cells, ${ }^{44}$ and umbilical cord cells ${ }^{45}$ all facilitate photoreceptor rescue in the RCS rat. Transplanted cells may be primary cells that have been collected immediately before transplantation, or can instead be cultured in vitro prior to transplantation. Alternatively, a transformed RPE cell line such as ARPE-19 or h1RPE-7 can be used, although these tend to be utilised only for experimental purposes because of the risk of teratoma formation in vivo. From the point of view of the transplanting surgeon, the original source of the cell is not as important as the technical aspects of collecting and delivery. Therefore, many types of cell sources can be used to produce a pure cell culture in vitro, but to the vitreoretinal surgeon what is more pertinent is whether the cells are to be transplanted as a cell sheet or as a suspension. From the surgical point of view, cell sources can be divided into three types:

- Autologous RPE cells (discussed in the previous section)

- Autologous IPE cells

- In vitro cultured allogenic cells 
a

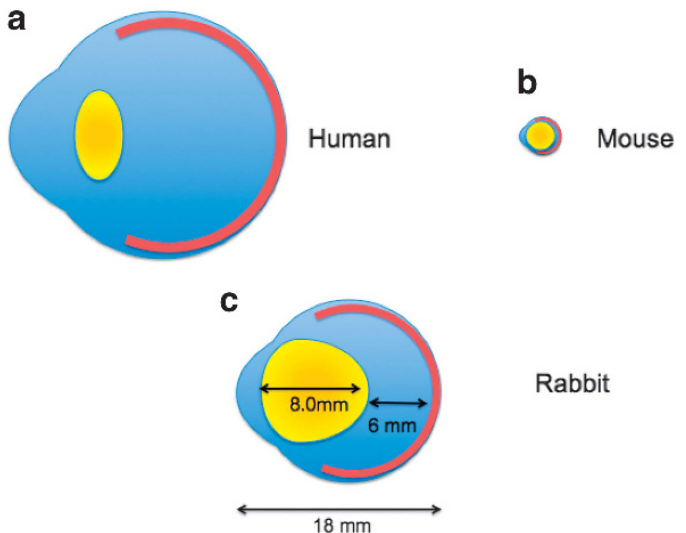

Figure 2 (a-c): Schematic diagrams of (a) human eye (b) mouse eye and (c) rabbit eye (shown to scale). Retinal surgery in the human eye is facilitated by the large vitreous cavity. Following surgical pars plana vitrectomy, a subretinal bleb can be created with a 41-gauge cannula, to create a space for the transplanted RPE. The mouse eye (b) is an unsuitable experimental model not only because the eye is so small (axial length approx. $3 \mathrm{~mm}$ ) but also because the lens is large and spherical and occupies most of the space within the globe. The vitreous cavity in the mouse eye is small and an epiretinal approach to RPE transplantation following pars plana vitrectomy is impossible. In contrast, the rabbit eye (c) is only slightly smaller than a human adult eye, and there is sufficient space within the vitreous cavity to allow pars plana vitrectomy and induction of a subretinal bleb. While the rabbit lens is larger than a human lens, intraoperative lens touch can be avoided with careful surgery. The rabbit eye is therefore an excellent model for RPE transplantation techniques.

\section{Autologous IPE cells}

IPE cells are a source for autologous cell transplantation because they are similar to RPE cells but are much easier to collect. ${ }^{46}$ Surgical iridectomy is a relatively straightforward procedure and iridectomy specimens have been successfully used to produce dissociated IPE cells that can be propagated in culture. ${ }^{47}$

RPE and IPE cells are derived from the same embryonic cell line, and both cell types have apical/basal polarisation, microvilli, and tight junctions that serve as a barrier to regulate the passage of ions and small molecules and to restrict diffusion of membrane lipids and proteins. Importantly, RPE and IPE tight junctions are morphologically similar. IPE cells can survive for up to 20 weeks in the subretinal space of rabbits ${ }^{48,49}$ and in vivo phagocytosis of photoreceptor outer segments of RCS rats has also been demonstrated..$^{50}$

Gene expression in IPE cells differs from that of RPE cells. Gene expression for intra- and extracellular retinal binding proteins, which are essential for metabolism of the visual pigments, is lower in IPE cells than RPE cells. ${ }^{51}$ In vitro, IPE cells are able to phagocytose photoreceptor outer segments but are less able to degrade them compared with RPE cells. ${ }^{52}$ The level of expression of
mRNA of VEGF is also lower in IPE cells than in RPE cells, ${ }^{53}$ but it has been suggested that this may in fact make IPE cells more suitable than RPE cells for subretinal transplantation, especially in cases of exudative AMD where presence of VEGF can stimulate recurrence of $\mathrm{CNV}^{46}$ It is not know to what degree IPE cells acquire RPE properties when transplanted into the subretinal space in patients with AMD. However, Abe et al report 56 AMD patients who underwent pars plana, vitrectomy, $\mathrm{CNV}$ excision, IPE transplantation into the subretinal space, and gas tamponade. Despite an initial deterioration in visual acuity, there was a long-term $\log M A R$ visual acuity improvement, with at least 2 years follow-up in all patients ( 1.26 vs $1.48, P=0.02$ ). Four of the 56 developed surgical complications including rhegmatogenous retinal detachment (three patients) and vasculitis (one patient). ${ }^{46}$

\section{Ex vivo cell sheet expansion prior to transplantation}

For nonautologous transplants, donor RPE cells can be removed from an enucleated eye cup either by using trypsin digestion for the collection of a cell suspension, or alternatively, dispase can be used to separate the basement membrane from the RPE monolayer, thereby allowing harvest of an intact RPE cell sheet. ${ }^{20}$ Authors who have utilised foetal human RPE cells have cultured the cells in vitro prior to surgical injection. Gouras et a ${ }^{54}$ excised a 0.6-mm RPE monolayer patch from foetal human RPE cells cultured in vitro, and by aspiration into a glass pipette were able to deliver the patch into the subretinal space. Primary cell cultures have a limited lifespan because after a number of population doublings (known as the Hayflick limit), cells undergo senescence and stop dividing. This is beneficial because while the cells retain viability there is very little risk of nonregulated growth. ${ }^{55}$

Transformed RPE cells can be defined as cell lines that have either spontaneously or deliberately acquired genetic modifications that lead to a state of unregulated growth. They are useful in cell culture because they show long-term stability in vitro. RPE cell transformations can occur spontaneously, such as with the ARPE19 and the D407 cell lines, ${ }^{56,57}$ but may also be genetically engineered for example, H1RPE7. ${ }^{58}$ RPE cells can also be genetically modified to alter some other aspect of their behaviour, so that they either express a marker (eg. Green Fluorescent Protein (GFP)-labelled RPE) or modify gene expression. However, after repeated passage it has been established that these adult human cell lines can dedifferentiate and lose their morphology and RPE gene expression, and express neuronal cell markers instead. ${ }^{59,60}$ 


\section{Pluripotent stem cells}

The use of stem cell technology holds promise as a novel source of cells for transplantation in AMD and other degenerative diseases. Stem cells are able to self-renew indefinitely, while maintaining a stable undifferentiated state, but are pluripotent and can, therefore, differentiate into any cell type in the body (except into placental cells). ${ }^{61}$ Human embryonic stem cells (hESCs) can be isolated from the inner cell mass of the human blastocyst at approximately five days post fertilisation. These cells can then be maintained indefinitely under defined conditions in vitro, as pluripotent cells, and, when required, can be differentiated into RPE cells. ${ }^{62}$ Using hESC-derived RPE, Lu et al have demonstrated photoreceptor rescue and sustained cell function in the RCS rat. The first use of hESC-derived RPE cells in human patients was described by Schwartz et al, in one patient with Stargardt's macular dystrophy and another with dry AMD. ${ }^{63}$ Initial results show no significant improvement in visual function, but do suggest a good safety profile. The use of hESC for RPE transplantation not only entails ethical obstacles, but also carries a risk of immune rejection, especially, as surgical trauma is likely to compromise the blood retinal barrier and the immune privilege status of the subretinal space.

The difficulties associated with hESC can be overcome with the use of induced pluripotent stem cells (iPSCs). This technology was first described in 2006 by Yamanaka, who was awarded the 2012 Nobel Prize for his work. ${ }^{64}$ This technique uses viral vectors to insert four key genes into the DNA of any mature somatic cell, which then causes reprogramming of the cell into a stem cell capable of producing any cell lineage of the three germ layers.

The intrinsic attraction of iPSC technology is not only the avoidance of the ethical issues of using embryonic cells, but also that iPSC-derived cell transplantation would obviate the need for continual immunosuppression. In a model scenario, tissue would be obtained from a somatic cell of the patient with AMD, the cells would be reprogrammed to a pluripotent state, and then differentiated into RPE cells and expanded in vitro, prior to transplantation. Autologous transplantation of iPS-derived RPE cells, without any artificial scaffold, into a nonhuman primate showed no immune rejection or tumour formation. However, the immunogenicity of iPSC has not been well studied and while they certainly have an advantage over ESC, there is some evidence that iPSC derivatives can induce T-cell-dependent immune responses even in genetically identical organisms. ${ }^{65}$

Rather than simply being used as a regenerative source, the use of iPSCs in combination with gene therapy may enrich their therapeutic potential. Autologous iPSCs could be screened for common genetic mutations that could then be corrected in vitro by gene therapy. Cells would then be differentiated into RPE cells before surgical transplantation. Assuming that sufficient photoreceptors remained functionally intact, this could allow a diseasefree phenotype to be maintained, but this tandem technique relies on complete elimination of any diseased host cells prior to transplantation. ${ }^{66}$

A significant concern associated with the use of iPSC technology is the risk of tumorigenicity. The four key genes used by Yamanaka all code for transcription factors: c-Myc, Sox2, Oct4, and Klf4. Of these, c-Myc is known to be an oncogene and the remaining factors have been implicated in tumorigenicity. Yu et al have demonstrated that a different combination of transcription factors-Oct4, Sox2, Lin28, and Nanog-can also induce pluripotency in human somatic cells, but Nanog is also known to be expressed in some tumours, and can promote breast cancer tumorigenesis and metastasis. ${ }^{67}$ The iPSC technology uses viral DNA that could incorporate itself into the genome of the somatic cell and potentially cause harm. However, an approach that uses nonintegrating adenoviruses, could avert the cancer risks of iPSCs, and no tumours have been observed in mice derived from integration-free iPSCs up to 20 weeks of age. ${ }^{68}$ However, exclusion of these oncogenic factors has a significant and detrimental effect on reprogramming efficiency and it is unknown whether reprogramming itself may lead to tumorigenesis. ${ }^{69,70}$

In 2014, Obokata reported that strong external stimuli, such as a transient low-pH stressor, can generate pluripotent stem cells without the need for transcription factor integration into the genome, has generated much excitement and controversy. This cellular reprogramming, known as stimulus-triggered acquisition of pluripotency (STAP), has not been reproduced despite fervent attempts by several other groups ${ }^{71,72}$ and the original paper has since been retracted. ${ }^{73}$ The observation by the original authors that STAP cell technology only seems to work on freshly collected cells from the early postnatal period suggests that this technology, even if reproducible, is unlikely to be of major benefit, and would certainly preclude its use for patients with AMD.

\section{Surgical instrumentation}

\section{Removing residual RPE}

A number of investigators have used animal models to determine the effects of removing the residual RPE prior to transplantation. Lopez et al used a diamond dusted needle but subsequent histological examination revealed numerous inadvertent breaks in BrM, resulting in cellular proliferation from the choroid into the subretinal space. ${ }^{35}$ 
This group therefore reverted to removing host RPE with the force of the subretinal fluid injection. However, this is also not ideal because the RPE is not removed, it simply remains attached to the underside of the neurosensory retina, thereby creating a different plane of separation. Following transplantation the host RPE lies between the transplanted cells and the photoreceptors.

Wongpichedchai et al used $100 \mu \mathrm{l}$ of $0.02 \%$ ethylenediaminetetraacetic acid (EDTA) to create subretinal blebs in rabbits. The EDTA was then aspirated, bringing RPE cells with it. These cells were of sufficient number to achieve in vitro culture. ${ }^{38}$

Stanzel et al have recently reported use of a $0.1 \mathrm{~mm}$ prolene loop to facilitate RPE removal. In a rabbit model, an area of $2.5 \mathrm{~mm} \times 1.5 \mathrm{~mm}$ was treated with a single forward and backward stroke. This area was later found to be $70 \%$ devoid of RPE cells, although a few miniscule BrM lacerations and choriocapillaris blood clots also occurred. A thinner, more flexible prolene loop was less effective, as was a $0.1 \mathrm{~mm}$ metal wire, which also caused intraoperative subretinal haemorrhage. ${ }^{74}$

\section{Delivery of an RPE cell suspension}

In their seminal experiments with the RCS rat, $\mathrm{Li}$ and Turner used a blunt needle to deliver a suspension of RPE cells into the subretinal space, via a transsclerochoroidal route. ${ }^{15}$ Lopez et al performed surgery in rabbits and were able to pass a glass cannula with an internal diameter of $100 \mu \mathrm{m}$ through the pars plana, and then create a small subretinal bleb via a retinotomy. ${ }^{35}$ The diameter of their glass cannula is similar to that of a 41-gauge needle, which is now used widely for formation of a localised retinal detachment during vitrectomy.

Similar to the methods of Lopez et al, Gouras and coauthors used a glass cannula to deliver RPE cells into the subretinal space in patients with dry AMD. ${ }^{54}$ They used the cannula to deliver either a cell suspension, or to deliver a patch transplant of cultured human foetal RPE. Although their attempts to inject an RPE cell suspension were largely successful, they were dissatisfied with the subretinal patch graft technique. The 0.6-mm diameter circular graft would fold in the subretinal space, and on histological examination the outer nuclear layer tended to be thinner over the folded RPE graft than when the photoreceptors were adjacent to a single (unfolded) RPE layer. Gouras et al did not use a BrM substitute and were simply cutting a circular patch of an RPE monolayer grown in tissue culture. The use of a BrM substitute would not only improve the chances of preventing photoreceptor degeneration but has the added advantage of providing some stability and rigidity to the graft.

Wongpichedchai compared internal and external approaches of RPE transplantation in rabbits, and identified differing challenges. For the external approach disinsertion of a rectus muscle was necessary to access the posterior pole. For the internal approach, a micropipette with an internal diameter of just $60 \mu \mathrm{m}$, drawn from glass, was used to induce a subretinal bleb. The micropipette was advanced vertically through the pars plana incision, to avoid trauma to the large crystalline lens in the rabbit eye. To ensure precise placement of the tip, and controlled injection of the RPE cell suspension, an electronic injection microsyringe manipulator was utilised. This ensured that at the point of the retinotomy, the cells were injected no more than $200 \mu \mathrm{m}$ deep to the inner retinal surface, and were injected at a constant controlled rate. ${ }^{38}$ Similarly, Weichel used a manual oil-hydraulic microinjection pump to achieve controlled subretinal infusions of RPE cells. ${ }^{75}$

\section{Delivery of a patch graft}

Maaijwee et $a l^{76}$ have done considerable work investigating different types of instrumentation for use with grafts of RPE-BrM-partial thickness choroid. The group compared traditional grasping forceps with an aspiration-reflux cannula manufactured by DORC, similar in design to the instrument utilised by Thumann et al, but found that the main difficulty with both methods was ensuring release of the graft once the tip of the instrument was in the subretinal space. To combat the friction between the graft and the carrier platform of the aspiration-reflux instrument, Maaijwee performed several laboratory experiments demonstrating that the ability to make the instrument vibrate, utilising either the linear motor of a loudspeaker, or the vibration function of a mobile phone, would allow successful dislodgement of the graft. These techniques are yet to be used in clinical or surgical practice. The same group have investigated the use of a microscale thermal tissue gripper which utilises heat induced attachment and detachment of the graft. ${ }^{77}$ Using chicken meat for experimental purposes, a greater than $90 \%$ success rate for graft attachment/detachment was observed. Owing to the small contact area of the instrument with the tissue, visible tissue damage was limited to only $0.005 \mathrm{~mm}^{2}$.

Thumann et al used a custom-made device to deliver an RPE cell sheet. ${ }^{42}$ The device consists of a perforated carrier platform, attached to a syringe which exerts a vacuum on the under surface of the graft, thereby preventing it from becoming dislodged. The platform is then covered by a second cannula, protecting the RPE cells from damage or dislodgement when introduced into the eye. Once the instrument tip was in the subretinal space, the second cannula was pulled back and a small amount of pressure was placed on the syringe plunger, allowing release of the graft. A modified version of the instrument had a tip angled at 45 degrees to allow easy 
access to the subretinal space. Thumann et al were able to ensure consistent delivery of the cell sheet, without rolling or folding, and simply used micro tweezers to ensure satisfactory positioning. ${ }^{42}$

Stanzel et al have described a custom-made implant shooter instrument to deliver polyester membrane inserts, some of which were gelatin covered, to facilitate implant loading and delivery. The investigators performed pars plana vitrectomy and induced a subretinal bleb with a 41gauge needle, and utilised a novel infusion cannula with two side ports, to reduce the stream of fluid over the subretinal bleb, thereby avoiding collapse of the bleb or uncontrolled tearing of the retinotomy. ${ }^{78}$ Despite elegant demonstration of delivery into the appropriate anatomical space, implantation of polyester implants without RPE cells resulted in development of a multilayered fibrocellular scar tissue, and almost complete atrophy of photoreceptors overlying the implant, with evidence of intraretinal cyst formation on OCT scanning. This may have occurred because of the mechanical separation of photoreceptors from the RPE by the implant. Similar atrophic changes have been observed after subretinal implantation of artificial retina chips and it was hypothesised that a more permeable carrier may result in a better preserved outer retinal architecture. ${ }^{78}$

Implantation into rabbit eyes of the polyester carrier with RPE derived from human embryonic stem cells resulted in $95 \%$ survival at four weeks. ${ }^{79}$

\section{Prevention and control of PVR}

PVR is an inflammatory and fibrotic process that occurs in patients with retinal holes or tears. It is caused by the migration and proliferation of RPE cells, and RPE cells have been identified in formed PVR membranes. ${ }^{80}$ The prospect of an iatrogenic, albeit localised, retinal detachment by creation of a retinotomy, followed by insertion of donor RPE cells on a scaffold, possibly preceded by debridement of the existing RPE, is likely to allow significant RPE migration into the vitreous cavity and subsequently on to the surface of the retina, leading to PVR membrane formation and contraction. PVR over the macula causes preretinal membrane formation. Contraction of this membrane can lead to visual distortion and visual loss. PVR over the peripheral retina can cause retinal traction and subsequent retinal detachment. At around 10\%, the rate of PVR development is similar for patients undergoing injection of a subretinal RPE cell suspension ${ }^{81}$ and patients receiving an RPEchoroid graft from within the macular area. ${ }^{25}$ Harvesting a peripheral RPE-choroid graft seems to produce a slightly higher rate of PVR and potential reasons for this include release of RPE cells during peripheral harvesting, traumatic enlargement of the macular retinotomy for graft insertion, or continued release of RPE postoperatively from the bed of the donor site. ${ }^{82}$ There is no demonstrable difference in PVR rate between superior and inferior donor sites, suggesting that there is no advantage from attempting to avoid the inflammatory aqueous milieu in the inferior retina that may not be in direct contact with tamponade. ${ }^{82}$

Although some authors report the use of pharmacological agents to prevent PVR development, none of these is used in routine clinical practice. The use of silicone oil as an intraocular tamponade has been well described in the prevention and control of PVR, ${ }^{83}$ although a recent Cochrane review could find no major difference between silicone oil and $\mathrm{C}_{3} \mathrm{~F}_{8}$ gas tamponade. ${ }^{84}$

\section{Future prospects}

There are a number of clinical trials already underway to evaluate the safety and efficacy of RPE cell transplantation for patients with AMD or other retinal degenerative disorders. Only one trial will use RPE cells derived from iPSC, and all other trials will use RPE cells that have been derived from hESCs. In addition to the challenges already described earlier, cells for transplantation need to meet strict standards of quality, quantity, consistency and safety, which in the UK are governed by the Good Manufacturing Practice (GMP) standard.

Ocata Therapeutics, formerly named Advanced Cell Technology, is a biotechnology company that provides ESC-derived RPE and is the sponsor of three separate Phase I/IIa trials to evaluate safety and tolerability of subretinal RPE transplantation in patients with one of three diseases: Advanced Dry AMD, Stargardt's Macular Dystrophy, and Myopic Macular Degeneration. In each of these trials, the study patients will undergo vitrectomy followed by subretinal injection of a cell suspension of RPE cells derived from ESC. The Advanced Dry AMD trial (ClinicalTrials.gov Identifier: NCT01344993) has recently reported its early findings. It recruited nine patients with dry AMD, and had three cohorts, each with three patients. Each cohort received a different number of transplanted RPE cells (50000, 100000 or 150 000). Of note, this trial did not attempt to replace BrM, nor does it deliver the transplanted RPE cells into the subretinal space as a polarised monolayer. This is only a safety/tolerability study, yet six of the nine patients showed a visual acuity improvement of at least 11 letters. The usefulness of RPE transplantation in patients in patients who already have poor vision owing to secondary photoreceptor atrophy is unclear. It is hoped that the subsequent Phase III trial will yield valuable information. 
The London Project to Cure Blindness (ClinicalTrials. gov Identifier: NCT01691261) aims to utilise human ESC to derive RPE cell sheets, rather than a cell suspension. This cell sheet will be supported by an engineered scaffold, to assist delivery and survival in the subretinal space of patients with recent rapid visual decline.

Masayo Takahashi leads the Laboratory for Retinal Regeneration at the Riken Institute in Japan, which has generated human iPS-derived RPE cell sheets without the use of any artificial scaffolds. A study of transplantation of a $1.3 \mathrm{~mm} \times 3 \mathrm{~mm}$ RPE cell sheet in human subjects with exudative age-related macular degeneration (JPRNUMIN000011929) is underway, with the first patient receiving transplantation in September 2014. This study is of great interest not only because of the decision to avoid using an artificial scaffold to support the RPE cells, but also because this is the first ever human clinical trial to use iPS-derived cells. The outcomes of this trial are anxiously awaited.

\section{Conflict of interest}

The authors declare no conflict of interest.

\section{Acknowledgements}

We are grateful to Dr Miguel Velazquez and Mr Alan Morris for their assistance with the illustrations in this article. We acknowledge funding support from the Brian Mercer Charitable Trust and the Global Ophthalmology Awards Program from Bayer.

\section{References}

1 Ambati J, Ambati BK, Yoo SH, Ianchulev S, Adamis AP. Age-related macular degeneration: etiology, pathogenesis, and therapeutic strategies. Surv Ophthalmol 2003; 48(3): 257-293.

2 Zarbin MA. Current concepts in the pathogenesis of agerelated macular degeneration. Arch Ophthalmol 2004; 122(4): 598-614.

3 Rosenfeld PJ, Brown DM, Heier JS, Boyer DS, Kaiser PK, Chung CY et al. Ranibizumab for neovascular age-related macular degeneration. N Eng J Med 2006; 355(14): 1419-1431.

4 Brown DM, Michels M, Kaiser PK, Heier JS, Sy JP, Ianchulev T. Ranibizumab versus verteporfin photodynamic therapy for neovascular age-related macular degeneration: Two-year results of the ANCHOR study. Ophthalmology 2009; 116(1): 57-65 e55.

5 Grunwald JE, Daniel E, Huang J, Ying GS, Maguire MG, Toth CA et al. Risk of geographic atrophy in the comparison of age-related macular degeneration treatments trials. Ophthalmology 2014; 121(1): 150-161.

6 Velez-Montoya R, Oliver SC, Olson JL, Fine SL, Mandava N, Quiroz-Mercado H. Current knowledge and trends in agerelated macular degeneration: today's and future treatments. Retina 2013; 33(8): 1487-1502.
7 Strauss $\mathrm{O}$. The retinal pigment epithelium in visual function. Physiol Rev 2005; 85(3): 845-881.

8 Miller SS, Steinberg RH. Active transport of ions across frog retinal pigment epithelium. Exp Eye Res 1977; 25(3): 235-248.

9 Miller SS, Steinberg RH. Passive ionic properties of frog retinal pigment epithelium. J Membr Biol 1977; 36(4): 337-372.

10 Hogan MJ. Ultrastructure of the choroid. Its role in the pathogenesis of chorioretinal disease. Trans Pac Coast Otoophthalmol Soc Annu Meet 1961; 42: 61-87.

11 Flood MT, Gouras P, Kjeldbye H. Growth characteristics and ultrastructure of human retinal pigment epithelium in vitro. Invest Ophthalmol Vis Sci 1980; 19(11): 1309-1320.

12 Boulton ME, Marshall J, Mellerio J. Human retinal pigment epithelial cells in tissue culture: a means of studying inherited retinal diseases. Birth Defects Orig Artic Ser 1982; 18 (6): 101-118.

13 Hu DN, Del Monte MA, Liu S, Maumenee IH. Morphology, phagocytosis, and vitamin A metabolism of cultured human retinal pigment epithelium. Birth Defects Orig Artic Ser 1982; 18(6): 67-79.

14 Mason C, Dunnill P. Quantities of cells used for regenerative medicine and some implications for clinicians and bioprocessors. Regen Med 2009; 4(2): 153-157.

15 Li LX, Turner JE. Inherited retinal dystrophy in the RCS rat: prevention of photoreceptor degeneration by pigment epithelial cell transplantation. Exp Eye Res 1988; 47(6): 911-917.

16 Dowling JE, Sidman RL. Inherited retinal dystrophy in the rat. J Cell Biol 1962; 14: 73-109.

17 D'Cruz PM, Yasumura D, Weir J, Matthes MT, Abderrahim $\mathrm{H}$, LaVail MM et al. Mutation of the receptor tyrosine kinase gene Mertk in the retinal dystrophic RCS rat. Hum Mol Genet 2000; 9(4): 645-651.

18 Gouras P, Kong J, Tsang SH. Retinal degeneration and RPE transplantation in Rpe65(-/-) mice. Invest Ophthalmol Vis Sci 2002; 43(10): 3307-3311.

19 Hawkins BS, Bressler NM, Miskala PH, Bressler SB, Holekamp NM, Marsh MJ et al. Surgery for subfoveal choroidal neovascularization in age-related macular degeneration: ophthalmic findings: SST report no. 11 Ophthalmology 2004; 111(11): 1967-1980.

20 da Cruz L, Chen FK, Ahmado A, Greenwood J, Coffey P. RPE transplantation and its role in retinal disease. Prog Retin Eye Res 2007; 26(6): 598-635.

21 Chen FK, Patel PJ, Uppal GS, Tufail A, Coffey PJ, Da Cruz L. Long-term outcomes following full macular translocation surgery in neovascular age-related macular degeneration. $\mathrm{Br}$ J Ophthalmol 2010; 94(10): 1337-1343.

22 Cahill MT, Stinnett SS, Banks AD, Freedman SF, Toth CA. Quality of life after macular translocation with 360 degrees peripheral retinectomy for age-related macular degeneration. Ophthalmology 2005; 112(1): 144-151.

23 Eckardt C, Eckardt U. Macular translocation in nonexudative age-related macular degeneration. Retina 2002; 22(6): 786-794.

24 Peyman GA, Blinder KJ, Paris CL, Alturki W, Nelson NC Jr., Desai U. A technique for retinal pigment epithelium transplantation for age-related macular degeneration secondary to extensive subfoveal scarring. Ophthalmic Surg 1991; 22(2): 102-108.

25 Stanga PE, Kychenthal A, Fitzke FW, Halfyard AS, Chan R, Bird AC et al. Retinal pigment epithelium translocation and central visual function in age related macular degeneration: preliminary results. Int Ophthalmol 2001; 23(4-6): 297-307. 
26 van Meurs JC, Van Den Biesen PR. Autologous retinal pigment epithelium and choroid translocation in patients with exudative age-related macular degeneration: short-term follow-up. Am J Ophthalmol 2003; 136(4): 688-695.

27 van Zeeburg EJ, Maaijwee KJ, Missotten TO, Heimann H, van Meurs JC. A free retinal pigment epithelium-choroid graft in patients with exudative age-related macular degeneration: results up to 7 years. Am J Ophthalmol 2012; 153(1): 120-127 e122.

28 Binder S, Stolba U, Krebs I, Kellner L, Jahn C, Feichtinger H et al. Transplantation of autologous retinal pigment epithelium in eyes with foveal neovascularization resulting from age-related macular degeneration: a pilot study. Am J Ophthalmol 2002; 133(2): 215-225.

29 Gullapalli VK, Sugino IK, Van Patten Y, Shah S, Zarbin MA. Retinal pigment epithelium resurfacing of aged submacular human Bruch's membrane. Trans Am Ophthalmol Soc 2004; 102: 123-138.

30 Carr AJ, Vugler AA, Hikita ST, Lawrence JM, Gias C, Chen LL et al. Protective effects of human iPS-derived retinal pigment epithelium cell transplantation in the retinal dystrophic rat. PLoS One 2009; 4(12): e8152.

31 Girman SV, Wang S, Lund RD. Cortical visual functions can be preserved by subretinal RPE cell grafting in RCS rats. Vision Res 2003; 43(17): 1817-1827.

32 Lee E, MacLaren RE. Sources of retinal pigment epithelium (RPE) for replacement therapy. Br J Ophthalmol 2011; 95(4): 445-449.

33 Gouras P, Lopez R. Transplantation of retinal epithelial cells. Invest Ophthalmol Vis Sci 1989; 30(8): 1681-1683.

34 Gouras P, Flood MT, Kjedbye H, Bilek MK, Eggers H. Transplantation of cultured human retinal epithelium to Bruch's membrane of the owl monkey's eye. Curr Eye Res 1985; 4(3): 253-265.

35 Lopez R, Gouras P, Brittis M, Kjeldbye H. Transplantation of cultured rabbit retinal epithelium to rabbit retina using a closed-eye method. Invest Ophthalmol Vis Sci 1987; 28(7): 1131-1137.

36 Peyman GA, Fishman GA, Sanders DR, Apple DJ, Vlchek JK. Biopsy of human scleral-chorioretinal tissue. Invest Ophthalmol 1975; 14(9): 707-710.

37 Lane C, Boulton M, Marshall J. Transplantation of retinal pigment epithelium using a pars plana approach. Eye (Lond) 1989; 3(Pt 1): 27-32.

38 Wongpichedchai S, Weiter JJ, Weber P, Dorey CK. Comparison of external and internal approaches for transplantation of autologous retinal pigment epithelium. Invest Ophthalmol Vis Sci 1992; 33(12): 3341-3352.

39 Remtulla S, Hallett PE. A schematic eye for the mouse, and comparisons with the rat. Vis Res 1985; 25(1): 21-31.

40 Stein JD, Zacks DN, Grossman D, Grabe H, Johnson MW, Sloan FA. Adverse events after pars plana vitrectomy among medicare beneficiaries. Arch Ophthalmol 2009; 127(12): 1656-1663.

41 Admitted Patient Care - England. Hospital Episode Statistics. Available at http://www.hscic.gov.uk/ searchcatalogue?productid=9161\&topics $=1 \% 2 \mathrm{fHospital}$ +care\%2fInpatient+admissions\&sort=Relevance\&size $=$ 10\&page $=1$ - top.

42 Thumann G, Viethen A, Gaebler A, Walter P, Kaempf S, Johnen $S$ et al. The in vitro and in vivo behaviour of retinal pigment epithelial cells cultured on ultrathin collagen membranes. Biomaterials 2009; 30(3): 287-294.
43 Lawrence JM, Sauve Y, Keegan DJ, Coffey PJ, Hetherington L, Girman S et al. Schwann cell grafting into the retina of the dystrophic RCS rat limits functional deterioration. Royal College of Surgeons. Invest Ophthalmol Vis Sci 2000; 41(2): 518-528.

44 McGill TJ, Cottam B, Lu B, Wang S, Girman S, Tian C et al. Transplantation of human central nervous system stem cells - neuroprotection in retinal degeneration. Eur J Neurosci 2012; 35(3): 468-477.

45 Lund RD, Wang S, Lu B, Girman S, Holmes T, Sauve Y et al. Cells isolated from umbilical cord tissue rescue photoreceptors and visual functions in a rodent model of retinal disease. Stem Cells 2007; 25(3): 602-611.

46 Abe T, Yoshida M, Yoshioka Y, Wakusawa R, Tokita-Ishikawa $\mathrm{Y}$, Seto $\mathrm{H}$ et al. Iris pigment epithelial cell transplantation for degenerative retinal diseases. Prog Retin Eye Res 2007; 26(3): 302-321.

$47 \mathrm{Hu}$ DN, McCormick SA, Ritch R. Isolation and culture of iris pigment epithelium from iridectomy specimens of eyes with and without exfoliation syndrome. Arch Ophthalmol 1997; 115(1): 89-94.

48 Crafoord S, Geng L, Seregard S, Algvere PV. Experimental transplantation of autologous iris pigment epithelial cells to the subretinal space. Acta Ophthalmol Scand 2001; 79(5): 509-514.

49 Crafoord S, Geng L, Seregard S, Algvere PV. Photoreceptor survival in transplantation of autologous iris pigment epithelial cells to the subretinal space. Acta Ophthalmol Scand 2002; 80(4): 387-394.

50 Rezai KA, Kohen L, Wiedemann P, Heimann K. Iris pigment epithelium transplantation. Graefes Arch Clin Exp Ophthalmol 1997; 235(9): 558-562.

51 Thumann G, Kociok N, Bartz-Schmidt KU, Esser P, Schraermeyer U, Heimann K. Detection of mRNA for proteins involved in retinol metabolism in iris pigment epithelium. Graefes Arch Clin Exp Ophthalmol 1999; 237(12): 1046-1051.

52 Dintelmann TS, Heimann K, Kayatz P, Schraermeyer U. Comparative study of ROS degradation by IPE and RPE cells in vitro. Graefes Arch Clin Exp Ophthalmol 1999; 237(10): 830-839.

53 Kociok N, Heppekausen H, Schraermeyer U, Esser P, Thumann G, Grisanti $S$ et al. The mRNA expression of cytokines and their receptors in cultured iris pigment epithelial cells: a comparison with retinal pigment epithelial cells. Exp Eye Res 1998; 67(2): 237-250.

54 Gouras P, Algvere P. Retinal cell transplantation in the macula: new techniques. Vision Res 1996; 36(24): 4121-4125.

55 Hayflick L, Moorhead PS. The serial cultivation of human diploid cell strains. Exp Cell Res 1961; 25: 585-621.

56 Dunn KC, Aotaki-Keen AE, Putkey FR, Hjelmeland LM. ARPE-19, a human retinal pigment epithelial cell line with differentiated properties. Exp Eye Res 1996; 62(2): 155-169.

57 Davis AA, Bernstein PS, Bok D, Turner J, Nachtigal M, Hunt RC. A human retinal pigment epithelial cell line that retains epithelial characteristics after prolonged culture. Invest Ophthalmol Vis Sci 1995; 36(5): 955-964.

58 Lund RD, Adamson P, Sauve Y, Keegan DJ, Girman SV, Wang $\mathrm{S}$ et al. Subretinal transplantation of genetically modified human cell lines attenuates loss of visual function in dystrophic rats. Proc Natl Acad Sci USA 2001; 98(17): 9942-9947.

59 Alge CS, Suppmann S, Priglinger SG, Neubauer AS, May CA, Hauck S et al. Comparative proteome analysis of native differentiated and cultured dedifferentiated 
human RPE cells. Invest Ophthalmol Vis Sci 2003; 44(8): 3629-3641.

60 Vinores SA, Derevjanik NL, Mahlow J, Hackett SF, Haller JA, deJuan E et al. Class III beta-tubulin in human retinal pigment epithelial cells in culture and in epiretinal membranes. Exp Eye Res 1995; 60(4): 385-400.

61 Thomson JA, Itskovitz-Eldor J, Shapiro SS, Waknitz MA, Swiergiel JJ, Marshall VS et al. Embryonic stem cell lines derived from human blastocysts. Science 1998; 282(5391): 1145-1147.

62 Carr AJ, Smart MJ, Ramsden CM, Powner MB, da Cruz L, Coffey PJ. Development of human embryonic stem cell therapies for age-related macular degeneration. Trends Neurosci 2013; 36(7): 385-395.

63 Schwartz SD, Hubschman JP, Heilwell G, Franco-Cardenas V, Pan CK, Ostrick RM et al. Embryonic stem cell trials for macular degeneration: a preliminary report. Lancet 2012; 379 (9817): 713-720.

64 Takahashi K, Yamanaka S. Induction of pluripotent stem cells from mouse embryonic and adult fibroblast cultures by defined factors. Cell 2006; 126(4): 663-676.

65 Zhao T, Zhang ZN, Rong Z, Xu Y. Immunogenicity of induced pluripotent stem cells. Nature 2011; 474(7350): 212-215.

66 Sancho-Martinez I, Li M, Izpisua Belmonte JC. Disease correction the iPSC way: advances in iPSC-based therapy. Clin Pharmacol Ther 2011; 89(5): 746-749.

67 Yu J, Vodyanik MA, Smuga-Otto K, Antosiewicz-Bourget J, Frane JL, Tian $S$ et al. Induced pluripotent stem cell lines derived from human somatic cells. Science 2007; 318(5858): 1917-1920.

68 Stadtfeld M, Nagaya M, Utikal J, Weir G, Hochedlinger K. Induced pluripotent stem cells generated without viral integration. Science 2008; 322(5903): 945-949.

69 Lu X, Zhao T. Clinical therapy using iPSCs: hopes and challenges. Genomics Proteomics Bioinformatics 2013; 11(5): 294-298.

70 Okita K, Yamakawa T, Matsumura Y, Sato Y, Amano N, Watanabe A et al. An efficient nonviral method to generate integration-free human-induced pluripotent stem cells from cord blood and peripheral blood cells. Stem Cells 2013; 31(3): 458-466.

71 Obokata H, Wakayama T, Sasai Y, Kojima K, Vacanti MP, Niwa $\mathrm{H}$ et al. Stimulus-triggered fate conversion of somatic cells into pluripotency. Nature 2014; 505(7485): 641-647.

72 Obokata H, Sasai Y, Niwa H, Kadota M, Andrabi M, Takata $\mathrm{N}$ et al. Bidirectional developmental potential in reprogrammed cells with acquired pluripotency. Nature 2014; 505(7485): 676-680.

73 Obokata H, Wakayama T, Sasai Y, Kojima K, Vacanti MP, Niwa $\mathrm{H}$ et al. Retraction: Stimulus-triggered fate conversion of somatic cells into pluripotency. Nature 2014; 511(7507): 112.

74 Stanzel BV, Thieltges F, Liu Z, Braun N, Wongsawad W, Somboonthanakij $\mathrm{S}$ et al. Localized RPE removal with a loop instrument in rabbits. Invest Ophthalmol Vis Sci 2014; 55(5): E-abstract 1179.

75 Weichel J, Valtink M, Engelmann K, Richard G. Use of an oilhydraulic microinjection pump for subretinal infusions. Ophthalmic Surg Lasers 2002; 33(4): 340-342.

76 Maaijwee K, Koolen T, Rosenbrand D, Jacobs E, Kleinheerenbrink S, Knulst A et al. Threshold Amplitude and Frequency for Ocular Tissue Release from a Vibrating Instrument: An Experimental Study. Invest Ophthalmol Vis Sci 2008; 49(4): 1629-1632.

77 Knulst AJ, Maaijwee K, van Meurs JC, Wieringa PA, Breedveld $\mathrm{P}$, Schutte $\mathrm{S}$. Micro-scale thermal tissue gripper. Minim Invasive Ther Allied Technol 2009; 18(1): 8-14.

78 Stanzel BV, Liu Z, Brinken R, Braun N, Holz FG, Eter N. Subretinal delivery of ultrathin rigid-elastic cell carriers using a metallic shooter instrument and biodegradable hydrogel encapsulation. Invest Ophthalmol Vis Sci 2012; 53(1): 490-500.

79 Stanzel BV, Liu Z, Somboonthanakij S, Wongsawad W, Brinken R, Eter N et al. Human RPE Stem Cells Grown into Polarized RPE Monolayers on a Polyester Matrix Are Maintained after Grafting into Rabbit Subretinal Space. Stem Cell Reports 2014; 2(1): 64-77.

80 Kirchhof B, Sorgente N. Pathogenesis of proliferative vitreoretinopathy. Modulation of retinal pigment epithelial cell functions by vitreous and macrophages. Dev Ophthalmol 1989; 16: 1-53.

81 Del Priore LV, Kaplan HJ, Hornbeck R, Jones Z, Swinn M. Retinal pigment epithelial debridement as a model for the pathogenesis and treatment of macular degeneration. Am J Ophthalmol 1996; 122(5): 629-643.

82 van Zeeburg EJ, Maaijwee K, van Meurs JC. There is no relation between the occurrence of proliferative vitreoretinopathy and the location of the donor site after transplantation of a free autologous retinal pigment epithelium-choroid graft. Acta Ophthalmol 2014; 92(3): 228-231.

83 Alexander P, Prasad R, Ang A, Poulson AV, Scott JD, Snead MP. Prevention and control of proliferative vitreoretinopathy: primary retinal detachment surgery using silicone oil as a planned two-stage procedure in high-risk cases. Eye (Lond) 2008; 22(6): 815-818.

84 Schwartz SG, Flynn HW Jr., Lee WH, Wang X. Tamponade in surgery for retinal detachment associated with proliferative vitreoretinopathy. Cochrane Database Syst Rev 2014; 2: CD006126. 